\title{
Cities, traffic, and $\mathrm{CO}_{2}:$ A multidecadal assessment of trends, drivers, and scaling relationships
}

\author{
Conor K. Gately ${ }^{1}$, Lucy R. Hutyra, and lan Sue Wing \\ Department of Earth and Environment, Boston University, Boston, MA 02215
}

Edited by Susan Hanson, Clark University, Worcester, MA, and approved March 13, 2015 (received for review November 12, 2014)

\begin{abstract}
Emissions of $\mathrm{CO}_{2}$ from road vehicles were 1.57 billion metric tons in 2012, accounting for $28 \%$ of US fossil fuel $\mathrm{CO}_{2}$ emissions, but the spatial distributions of these emissions are highly uncertain. We develop a new emissions inventory, the Database of Road Transportation Emissions (DARTE), which estimates $\mathrm{CO}_{2}$ emitted by US road transport at a resolution of $1 \mathrm{~km}$ annually for 19802012. DARTE reveals that urban areas are responsible for $80 \%$ of on-road emissions growth since 1980 and for $63 \%$ of total 2012 emissions. We observe nonlinearities between $\mathrm{CO}_{2}$ emissions and population density at broad spatial/temporal scales, with total on-road $\mathrm{CO}_{2}$ increasing nonlinearly with population density, rapidly up to 1,650 persons per square kilometer and slowly thereafter. Per capita emissions decline as density rises, but at markedly varying rates depending on existing densities. We make use of DARTE's bottom-up construction to highlight the biases associated with the common practice of using population as a linear proxy for disaggregating national- or state-scale emissions. Comparing DARTE with existing downscaled inventories, we find biases of $100 \%$ or more in the spatial distribution of urban and rural emissions, largely driven by mismatches between inventory downscaling proxies and the actual spatial patterns of vehicle activity at urban scales. Given cities' dual importance as sources of $\mathrm{CO}_{2}$ and an emerging nexus of climate mitigation initiatives, high-resolution estimates such as DARTE are critical both for accurately quantifying surface carbon fluxes and for verifying the effectiveness of emissions mitigation efforts at urban scales.
\end{abstract}

emissions | carbon dioxide | urban | transportation | on-road

$\mathbf{T}$ he United States, with 5\% of the world's population and 30\% of the world's automobiles, emits $45 \%$ of global transportation $\mathrm{CO}_{2}$ emissions (1). Nationally, the on-road sector represented $28 \%$ of total fossil fuel $\mathrm{CO}_{2}$ emissions in 2012 and is responsible for almost half of the growth in total US emissions since 1990 (2). Despite being a substantial component of US emissions, on-road $\mathrm{CO}_{2}$ remains poorly quantified at substate and urban scales (3-5). Reducing the uncertainty of on-road $\mathrm{CO}_{2}$ emissions at finer spatial scales is critical to understanding the determinants of motor vehicle emissions (3), constraining carbon budgets (4), and supporting greenhouse gas (GHG) emission monitoring and abatement verification (5), particularly at the scale of cities, which have emerged as hubs of climate change mitigation activity (6).

Carbon cycle models now operate at resolutions much finer than US states, and their reliance on gridded inventories for a priori estimates of the spatial distribution of emissions (7-9) means that raw emissions data available at coarse spatial scales must be "downscaled" to match model grids. Increasing the spatial resolution of emission inventories has been shown to change modeled terrestrial carbon flux estimates by more than $50 \%$ (8). The notion that population density is a robust predictor of $\mathrm{CO}_{2}$ emissions underpins most gridded global emissions estimates (10-14). Early studies used maps of population density to distribute national $\mathrm{CO}_{2}$ emissions on a global $1^{\circ}$ grid, assuming uniform per capita emissions within each country $(10,11)$. This assumption was shown to be invalid for the United States, where per capita emissions vary by an order of magnitude across states (12). Population becomes an even less reliable predictor of total
$\mathrm{CO}_{2}$ emissions at finer scales, where local patterns of concentrated point and line sources dominate over more diffuse area sources $(3,13)$. Used alone, population may be a valid predictor for residential and commercial sector emissions, but it performs poorly when used to model emissions from power stations or the on-road sector $(3,4,13)$. Recent global inventories, such as the Fossil Fuel Data Assimilation System, partially correct for this deviation by modeling power plant emissions directly as point sources, although on-road emissions are still spatially allocated using population and luminosity data (15). The Emissions Database for Global Atmospheric Research (EDGAR, version 4.2) used a wide variety of sector-specific variables to allocate national $\mathrm{CO}_{2}$ emissions onto a $0.1^{\circ}$ global grid (14), but it used only road density to distribute emissions spatially (16). In the United States, there is substantial variation in the intensity of vehicle activity per mile of roadway, as well as considerable differences in the fleet composition and fuel economy of vehicles that travel on different functional classes of roads (17-19).

A multivariate regression framework that broadens the number of proxies to incorporate demographic, socioeconomic, and built-environment variables appears to improve the spatial accuracy of predicted emissions. Individuals' vehicle travel was found to be best predicted by household income, vehicle ownership, and commuting distance, and the estimated relationships have been used to impute on-road emissions at the zip code level (20). Directly measured roadway $\mathrm{CO}_{2}$ concentrations have also been parsimoniously modeled using only the local fraction of impervious surface and a traffic volume-weighted road density index (21). In selected US states and cities, local traffic count data and state-level fuel consumption have been used to downscale emissions to a 500-m grid (22).

\section{Significance}

We use roadway-level traffic data to construct a 33-year, highresolution inventory of annual on-road $\mathrm{CO}_{2}$ emissions for the United States that differs markedly from other emissions estimates. We find a highly nonlinear relationship between population density and emissions, and identify large biases in regional estimates of $\mathrm{CO}_{2}$ from inventories that rely on population as a linear predictor of vehicle activity. Geographic differences in the density-emissions relationship suggest that "smart growth" policies to increase urban residential densities will have significantly different effects on emissions depending on local conditions, and may be most effective at low densities. Our results highlight the importance of cities as sources of $\mathrm{CO}_{2}$ and the need for improved fine-scale inventories for monitoring and reporting of emissions.

Author contributions: C.K.G., L.R.H., and I.S.W. designed research, performed research, analyzed data, and wrote the paper.

The authors declare no conflict of interest.

This article is a PNAS Direct Submission.

Freely available online through the PNAS open access option.

${ }^{1}$ To whom correspondence should be addressed. Email: cgately@gmail.com.

This article contains supporting information online at www.pnas.org/lookup/suppl/doi:10. 1073/pnas.1421723112/-/DCSupplemental. 


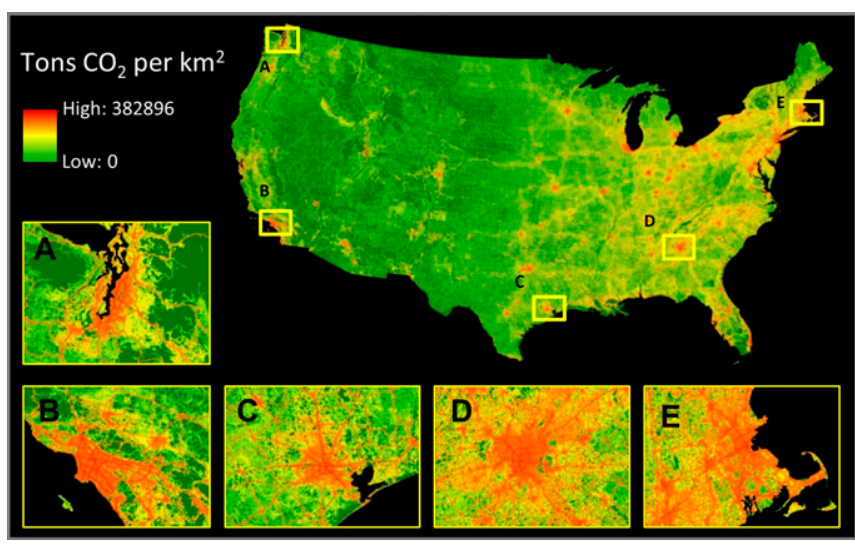

Fig. 1. Map of 2012 on-road $\mathrm{CO}_{2}$ emissions for the coterminous United States and selected urban areas at a resolution of $1 \mathrm{~km}$. (Insets) Maps show details of metro areas surrounding Seattle $(A)$, Los Angeles $(B)$, Houston (C), Atlanta $(D)$, and Boston $(E)$.

Most of these studies relied on cross-sectional data, which means that the temporal stability of their results remains untested. This issue is important for addressing the enduring question in urban sustainability of how trends in urban sprawl and densification affect individuals' travel behavior and related $\mathrm{CO}_{2}$ emissions over time (23-25). Population density is not thought to affect travel behavior directly, but it is a proxy for less easily measured characteristics of the urban environment [e.g., public transit availability, walkability, amenity access $(26,27)]$ whose impacts on travel have long been a focus of regional and urban planning research. A classic example is the exponential decline in per capita transportation energy use with increasing population density that was observed in a large cross-section of cities worldwide (28). This relationship suggests that urban densification reduces per capita emissions, an idea that has gone on to influence urban development and sustainability initiatives worldwide. Despite recent advances in this area $(29,30)$, there remains a fundamental simultaneity that confounds inferences about the density-emissions relationship: Individuals' travel behavior is affected by the built environment context of their place of residence, but their choice of residential location is simultaneously influenced by their travel preferences (31).

To unravel the joint spatial and temporal covariation between multiple predictors and emissions, we constructed a new, dynamic, process-based emissions inventory. The Database of Road Transportation Emissions (DARTE) is an annual 1-km resolution $\mathrm{CO}_{2}$ emissions inventory for the US on-road transportation sector, based on archived data of roadway-level vehicle traffic for the years 19802012. Raw vehicle activity data were obtained from the Federal Highway Administration's (FHWA's) Highway Performance Monitoring System (HPMS), a database of road-level traffic counts derived from annual reporting by all US state transportation departments (32). The availability of source activity data at this resolution enabled us to estimate vehicle emissions directly at the scale of individual road segments without the need to downscale emissions using spatial predictors. We combined HPMS roadway-level vehicle miles traveled (VMT) with year- and state-specific emissions factors for five vehicle types to calculate $\mathrm{CO}_{2}$ emissions from motor gasoline and diesel fuel consumption on six classes of urban and rural roads. We then used DARTE to quantify the spatiotemporally varying effects of population density, income, employment, and transit use on on-road $\mathrm{CO}_{2}$ emissions across the United States. We also characterize multidecadal trends in emissions across all rural and urban road types, finding an increasing dominance of urban emissions across the United States. Finally, we compared DARTE with several existing inventories of on-road $\mathrm{CO}_{2}$ emissions and identified large relative biases in emissions estimates, with differences that exceed $500 \%$ for several major US metropolitan areas.

\section{Results}

DARTE highlights the large spatial variations in on-road $\mathrm{CO}_{2}$ emissions that exist across the coterminous United States (Fig. 1). The 1-km spatial resolution rectifies sharp gradients in emissions around freeways and expressways, particularly in major urban areas. Total US on-road emissions increased by $50 \%$ from 1.04 gigatonnes (Gt) in 1980 to $1.55 \mathrm{Gt}$ in 2012 , with $80 \%$ of this increase occurring in urban areas. Rural emissions were 556 megatonnes (Mt) in 2012, an overall increase of $23 \%$ since 1980 , but there has been a notable recent decline from the peak of 637 Mt in 2002. Following 2002, trends for diesel and gasoline vehicles diverged, with rural gasoline emissions declining steadily and rural diesel emissions continuing to rise until the global economic recession in 2008 (Fig. 2). In contrast, urban area gasoline emissions rose steadily throughout the study period, despite the observed decline in overall emissions between 2008 and 2012.

Between 1980 and 2010, the US urban population grew by 81 million people, an increase of $49 \%$, whereas urban per capita emissions of on-road $\mathrm{CO}_{2}$ grew by $15 \%$ (Fig. 3). Although the rural area population declined slightly from 1980 to 2010, rural per capita emissions rose by $22 \%$ over that time. Nationally, per capita emissions peaked in 2004, although rural and suburban per capita emissions have begun to rise again since 2009 (Fig. 3). The sustained decline in urban per capita emissions is consistent with previous findings on the influence of residential density on vehicle travel (29); however, it is worth noting that before the peak in 2004, urban per capita emissions rose $19 \%$ from 1980 levels, whereas average urban population density rose $30 \%$ over the same time period. This discrepancy suggests that the future trajectory of per capita on-road emissions may not be as strongly coupled with trends in urban densification as previously believed. A confounding factor in analyzing trends in "urban" variables over time is that definitions of urban boundaries are not stable, because the US Census Bureau revises urbanized area definitions with each decadal census. However, US county boundaries have remained largely unchanged since 1980, as have the designated "central" and "outlying" counties located at the cores and peripheries, respectively, of most urbanized areas. To avoid any spatiotemporal biases induced by shifting urbanized area boundaries, we focused our further analysis on emissions at the county scale.

To elucidate the drivers of on-road emissions, we adopted a nonparametric, nonlinear modeling approach that characterized the functional forms of the relationships between on-road $\mathrm{CO}_{2}$,

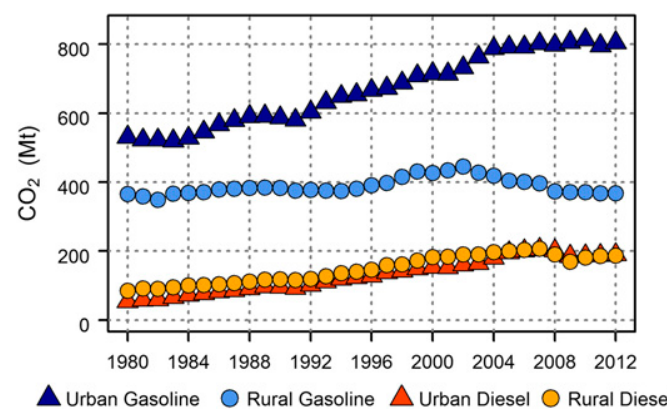

Fig. 2. Time series of US on-road $\mathrm{CO}_{2}$ emissions. Urban roads accounted for $80 \%$ of total emissions growth since 1980 . Rural road emissions have been declining since 2002 . 
income, employment, and population density, while controlling for spatial and temporal fixed effects. A cross-section/time series generalized additive model was used to model $\mathrm{CO}_{2}$ by fitting nonparametric splines to population density, per capita income, retail and nonretail job density, and a lagged population growth term as follows:

$$
\begin{aligned}
\mathrm{CO}_{2_{i, t}}= & \alpha_{i}+\tau_{t}+\Psi_{1}\left[\left(\begin{array}{c}
\text { Population } \\
\text { density }
\end{array}\right)_{i, t-1}\right]+\Psi_{2}\left[\left(\begin{array}{c}
\text { Per capita } \\
\text { income }
\end{array}\right)_{i, t-1}\right] \\
& +\Psi_{3}\left[\left(\begin{array}{c}
\text { Retail jobs } \\
\text { per km }
\end{array}\right)_{i, t-1}\right]+\Psi_{4}\left[\left(\begin{array}{c}
\text { Nonretail jobs } \\
\text { per km }
\end{array}\right)_{i, t-1}\right] \\
& +\Psi_{5}\left[(\text { Population })_{i, t-1}-(\text { Population })_{i, t-2}\right]+\varepsilon_{i, t} .
\end{aligned}
$$

Here, $i$ and $t$ index counties and years; parameters $\alpha$ and $\tau$ represent county fixed effects and year effects, respectively; and $\varepsilon$ is a random disturbance term. The terms of interest, $\Psi_{1}-\Psi_{5}$, are nonlinear spline functions defined over population density and statistical control variables, lagged 1 y to reduce simultaneity bias. The same model specification was also used to model per capita $\mathrm{CO}_{2}$ emissions. Model diagnostics and summary statistics are included in SI Appendix. The adjusted $R^{2}$ was 0.98 and 0.88 for the total and per capita emissions models, respectively. The estimated density-emissions relationship $\left(\Psi_{1}\right)$ shows $\mathrm{CO}_{2}$ increasing rapidly with population density below 1,650 persons per square kilometer before attaining a local maxima (Fig. $4 A 1$ ), consistent with previous findings for Massachusetts towns (3). This trend corresponds to the relatively slow decline in per capita emissions, with densities between 250 and 1,250 persons per square kilometer. Per capita emissions decrease more rapidly with density from 1,250-3,500 persons per square kilometer, which results in a plateau in total emissions at these densities (Fig. 4A2). Total emissions begin to rise again as density exceeds 4,000 persons per square kilometer, and per capita emissions cease to decline.

The potential for stabilizing on-road $\mathrm{CO}_{2}$ emissions in the United States is limited by the fact that in 2012 , only 46 counties (comprising $13 \%$ of the US population) had a population density greater than 1,000 persons per square kilometer. For the remaining $87 \%$ of the US population that lives in lower density counties, our results indicate that the ongoing urban growth in these counties is likely to produce substantial increases in local on-road emissions, because the reductions in per capita emissions at lower levels of urban density will not be sufficient to stabilize the total emissions growth. Since 2000, the 50 fastest growing counties by population experienced average increases in total on-road emissions of roughly $15 \%$, whereas their average per capita emissions fell by only $12 \%$. The average population density of these counties was only 350 persons per square kilometer in 2012, which is well below the densities our model indicates are needed to stabilize total on-road emissions on a county scale. Nationally, urban growth and residential densification should continue to reduce total on-road emissions, but in many of the fastest growing urban areas, total on-road emissions are likely to continue their steady increase. This discrepancy presents a potential tension between climate change policy at national and regional scales, because the reductions in national emissions provided by urbanization will not necessarily occur in the urban areas that are actually growing denser. From a regional planning perspective, it may make more sense for policy makers to focus on reducing local per capita emissions, rather than total emissions, because most growing urban areas should expect total on-road emissions to continue to rise with the population over the next decades.

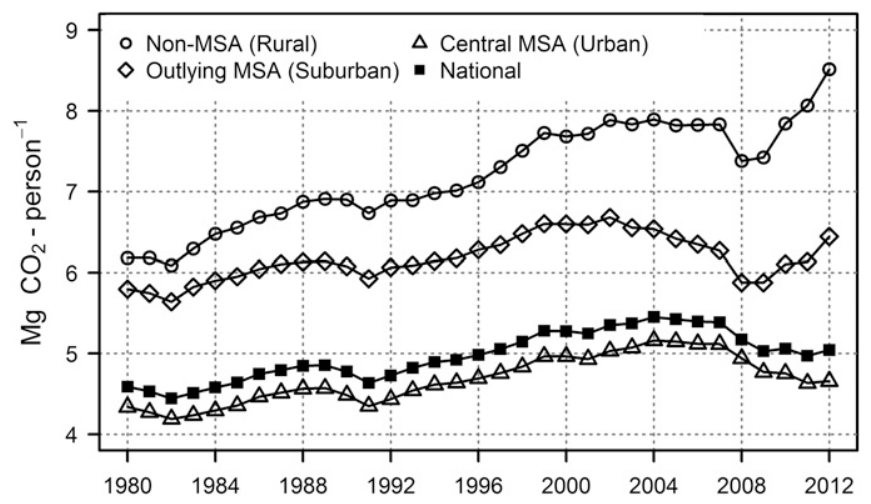

Fig. 3. Time series of US per-capita on-road $\mathrm{CO}_{2}$ emissions by county, using a Census 2000 Metropolitan Statistical Area (MSA) classification. Per capita emissions increased from 1980, both in urban and nonurban counties, with brief declines during the 1981-1982, 1990-1991, and 2007-2009 economic recessions. Since 2009 per capita emissions in non-MSA (rural) and outlying MSA (suburban) counties have grown rapidly, whereas central MSA (urban) per capita emissions have continued to decrease.

To expand our analysis beyond counties, and to test the stability of the density-emissions relationship, we reproduced per capita emission-density plots for the selection of US cities used by Newman and Kenworthy (28), but expanded the cross-sectional panel by using DARTE to generate a decadal time series of emissions estimates for each city (Fig. $4 B$ and $D$ ). We used census-designated places (CDPs) to define the boundaries of the core city areas, because these boundaries are the finest resolution spatial boundaries that have remained unchanged since 1980. We found significantly different trends in the per capita emissions-density relationship for cities whose densities fall above and below 1,650 persons per square kilometer. Cities such as Atlanta, Salt Lake City, and Phoenix experienced large increases in per capita emissions despite minimal changes in population density between 1990 and 2010, whereas San Francisco and Boston exhibited declining per capita emissions with rising density over the same time period (Fig. 4B). The divergence of trends in per capita emissions for cities on either side of 1,650 persons per square kilometer is consistent with the shape of $\Psi_{1}$ in Fig. $4 A 1$, which shows increasing total emissions at densities below this threshold and varying trends for densities between 1,650 and 4,000 persons per square kilometer. The results in Fig. $4 B$ provide evidence that the emissions-density relationships revealed in Fig. $4 A 1$ and $A 2$ hold true at the smaller spatial scales.

When the subset of cities in Fig. $4 B$ is overlaid on data from all other CDPs in the United States, we see that the sample of major cities used by Newman and Kenworthy (28) is a poor representation of the underlying emissions-density distribution across all CDPs. We observed a very large variation in per capita emissions across the lower density CDPs and considerable variation at higher densities as well. Although there appears to be a generally decreasing trend between per capita emissions and density, the spread of the data emphasizes the influence of additional covariates beyond population density on emissions at this spatial scale.

The processes that generate road-sector emissions are influenced by multiple factors, of which population density is only one partial component. We were unable to evaluate the impact of other factors, such as public transit use, in our regression model directly due to the unavailability of transit data through time at county scales. We plotted decadal census data on public transit use for the same sample of cities as in Fig. $4 B$, and found that cities with large public transit use shares do tend to have lower per capita emissions (Fig. 4C), although these trends were 

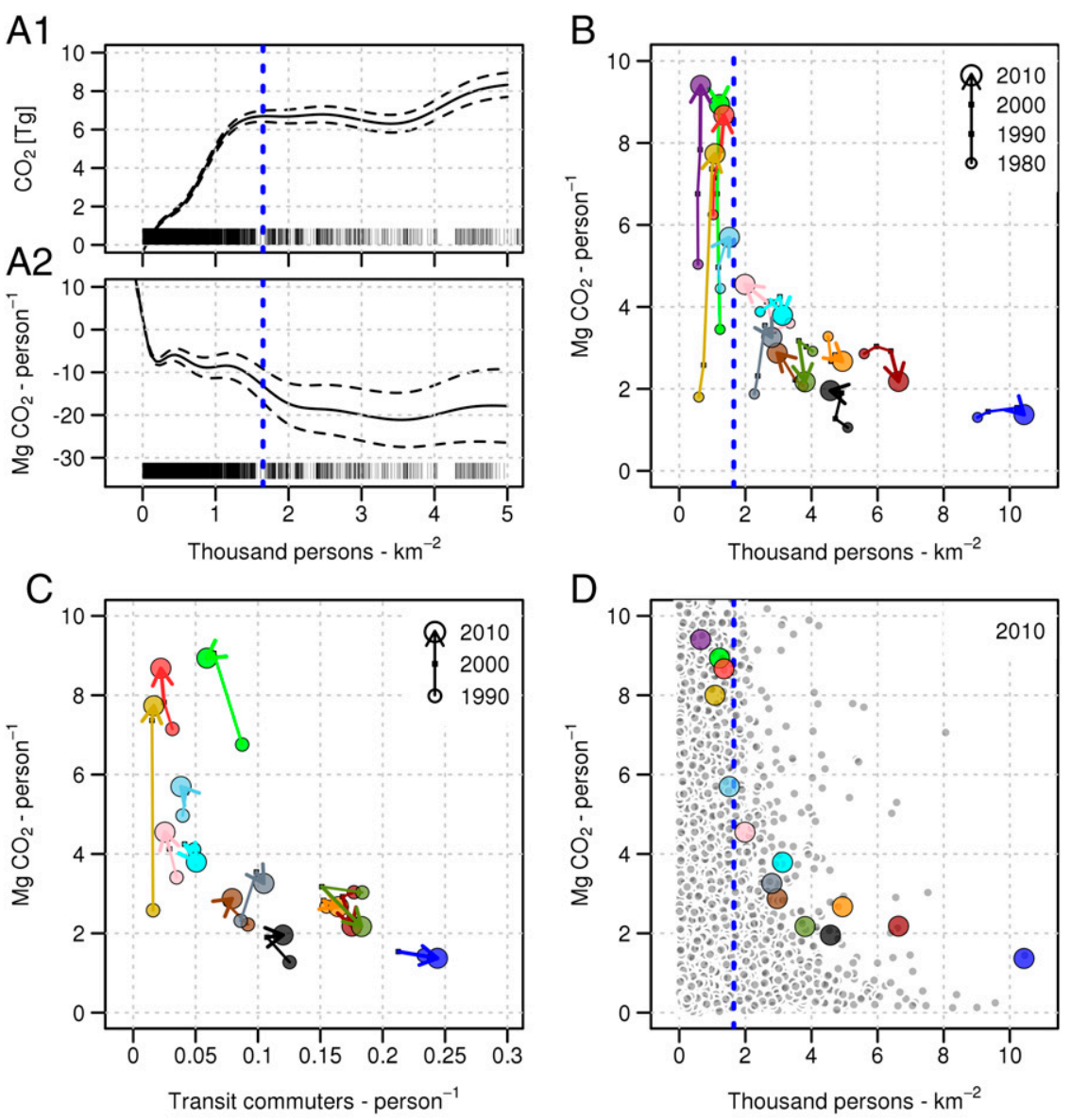

Fig. 4. Plots of on-road emissions at multiple scales. (A1 and A2) The fitted spline $\Psi_{1}$ for the partial prediction of total on-road $\mathrm{CO}_{2}$ in teragrams $(\mathrm{Tg})$ and per capita $\mathrm{CO}_{2}$ in megagrams $(\mathrm{Mg})(\mathrm{A} 1$ and $\mathrm{A} 2$, respectively), is plotted against county population density. The rug plots show the distribution of US counties pooled across all years. The values of $\Psi_{1}$ are the model-estimated emissions relative to the conditional mean of each county. (B) Decadal per capita emissions vs. density for 14 US cities. Movement in time is denoted by point size and arrows. (C) Per capita on-road $\mathrm{CO}_{2}$ plotted vs. the share of residents who commute using public transit. (D) Same cities as in $B$, overlaid on all US census-designated places (gray points), for the year 2010. The dashed blue line in $A 1, A 2, B$, and $D$ identifies the first local maxima of $\Psi_{1}$ at 1,650 persons per square kilometer.
- Atlanta, GA
- Baltimore, MD
- Boston, MA
- Denver, CO
- Detroit, MI
- Chicago, IL

\author{
- New York City, NY S Seattle, WA \\ - Phoenix, AZ Washington, DC \\ - Salt Lake City, UT
}
- San Francisco, CA

less consistent over time than trends in population density. Cities with a high population density also tend to have higher per capita transit shares. For the cities with a lower population density and lower transit shares, we observed higher per capita emissions in the more recent data (2000 and 2010). As with the plots of population density, the observed rise in per capita emissions over time in low-density cities suggests that public transit ridership has not had a significant effect on emissions trends in these cities since 1990. The only cities that show a clear correlation between increased transit share and decreased emissions are the cities with a $>15 \%$ transit share of the overall population. San Francisco; Washington, DC; and Boston all show noticeable decreases in per capita $\mathrm{CO}_{2}$ emissions between 2000 and 2010, concurrent with increases in the transit use share of their total population. With the limited sample size available, it is difficult to make conclusions about the large number of cities with lower population densities, and presumably lower shares of public transit use. The correlations between population density, employment density, income, and lagged population growth estimated by our model suggest that these factors may be sufficient to explain the majority of variance in on-road emissions at the county scale (SI Appendix, Figs. S5 and S6), but further research into the influence of urban typology and mobility patterns will be vital to understanding emissions trends at city and municipal scales.

Inventory Bias and Spatial Proxies. External validation of emission inventories is hampered by the lack of independent measure- ments of source activity (4), but it is informative to compare the effects of different model methodologies and proxy performance on the consistency of emissions estimates. Because DARTE estimates were not calculated using population or road density, we were able to evaluate the performance of these variables as spatial predictors by comparing DARTE with other well-known inventories. We aggregated DARTE's roadway-scale emissions to match the native resolutions of EDGAR (14) and the Vulcan Project (33). EDGAR is a $0.1^{\circ}$ gridded global emissions inventory product, with annual sector-level $\mathrm{CO}_{2}$ emissions reported through the year 2008. The Vulcan Project reports hourly sectorlevel emissions on a $10-\mathrm{km}$ grid for the United States for the year 2002. For on-road emissions, EDGAR uses road density as the sole spatial proxy to downscale national-level emissions (16). On-road emissions in the Vulcan Project were derived from VMT from the Environmental Protection Agency (EPA) National County Database (NCD). The NCD contains state-level VMT data that have been downscaled to counties using road and population density, with the exception of a small subset $(5 \%)$ of counties that reported VMT directly (34).

National emission totals of the Vulcan Project and EDGAR were similar to the national emissions total of DARTE, but when compared on a cell-by-cell basis, large deviations in emissions were observed. EDGAR exceeded DARTE by as much as $500 \%$ in some urban centers, whereas estimates of the Vulcan Project exceeded DARTE estimates by $50 \%$ or more in nearly $40 \%$ of grid cells (SI Appendix, Figs. S1-S4). In contrast to EDGAR, 
however, the Vulcan Project showed large negative biases relative to DARTE in the cores of large cities and positive biases as high as $100 \%$ in surrounding suburban and exurban areas. EDGAR's use of road density as a sole proxy assumes a uniform emission factor per kilometer of road, resulting in overallocation of emissions to low-traffic roads and underallocation to high-traffic roads. Although many urban roads carry large amounts of traffic, and hence are responsible for the majority of emissions, urban areas also contain a substantial fraction of local roads that are comparatively lightly traveled. EDGAR's use of a constant emission factor across road classes with very different activity levels would explain the positive bias in urban core areas with high road density and the negative bias in suburbs with sparser, but still highly traveled, roads.

For the Vulcan Project, the relative biases may be explained by how the VMT activity data are downscaled in the NCD. In the NCD, urban nonhighway VMT is redistributed from census urbanized areas to counties using population shares, whereas rural nonhighway VMT is downscaled from state totals, also using population. The results of our regression model (Fig. 4) indicate that on-road emissions (and, by implication, VMT) do not vary linearly with population. The use of population to redistribute VMT from urbanized areas to counties will produce spatial biases, because population density, and therefore per capita emissions rates, will vary substantially from the urban core to the suburban periphery (Fig. 3). The fact that the aggregated emissions estimates of DARTE, EDGAR, and Vulcan are in relative concordance, despite local differences of $500 \%$ or more for cityscale regions, underscores the risk in presuming that state-level VMT can be accurately downscaled to subcounty scales for the purpose of emissions modeling.

Uncertainty in On-Road Emissions. Uncertainty in the magnitude of on-road emissions at the national level is estimated to be on the order of $3-5 \%$ for developed countries $(4,35)$, but at subnational or state scales, existing inventories disagree by as much as $40 \%$ (3), and at city scales, uncertainty can be as large as $50-100 \%$ (13). Direct quantification of the uncertainty in US on-road emissions is made impossible by the absence of independent data sources against which to compare government estimates (4). Consequently, emissions uncertainty tends to be characterized in terms of the inherent variability of major data inputs to inventory construction: traffic sensor measurements, spatial imputation of VMT to roads that lack permanent sensors, and emissions factors used to convert VMT to $\mathrm{CO}_{2}$.

Traffic sensors are widely considered to measure total vehicle volumes with 95-99\% accuracy (36); therefore, we focused on estimating the potential uncertainty associated with the spatial imputation of VMT and the emissions factors used by DARTE. We examined the former by calculating within-county coefficients of variation (CVs) for VMT in each road class and year, and we found that urban and rural freeways and urban nonfreeway roads have consistently low variation in VMT, with CVs ranging from 0.4 to 1.1 on average. Rural nonfreeway VMT shows the most subcounty variation, with a mean CV of 2.4 and CVs as high as 14 in a handful of counties (SI Appendix, Fig. S9). Rural road segments are typically the least sampled roads in the HPMS, and are held to lower standards of precision by the FHWA (37). Rural nonfreeways also account for only $17 \%$ of total VMT; thus, although the spatial uncertainty of emissions from these roads is larger than from other functional class roads, their contribution to the total uncertainty is modest. We calculated similar statistics for the within-state, between-county variation of VMT to test the scale dependence of variation in VMT. The within-state CV of urban VMT ranged from 0.5 to 4.0 across all states and years, whereas rural VMT ranged more narrowly from 0.75 to 1.75 . This larger variation in urban VMT reflects the broader range of urban area sizes at state scales, because small and large cities have very different levels of vehicle activity.

Within-state CVs of emissions intensity $\left(\mathrm{CO}_{2} / \mathrm{VMT}\right)$ were found to be small, ranging from $0.1-0.2$ on average. Low variation in emissions relative to VMT corroborates previous findings that uncertainty in vehicle fleet and fuel economy characteristics are a minor contributor to the overall uncertainty in emissions estimates from the on-road sector (35). The relatively low variation in roadway-level VMT suggests that the uncertainty associated with spatially aggregating VMT from the roadway to the county scale is relatively small, so long as stratification by functional class is maintained. Greater variation in between-county urban VMT implies that downscaling VMT from state to county scales may result in a higher uncertainty associated with urban emissions, depending on the distribution of urban area size and local travel trends within the state.

Implications. Over the past 40 years, the global urban population rose from 1.51 to 3.91 billion people, and it is expected to reach 6.3 billion people by 2050 (38). $\mathrm{CO}_{2}$ emissions from transportation comprised $23 \%$ of global fossil fuel carbon emissions in 2010 (39), with over $40 \%$ of those emissions produced by road travel in urban areas (40). As the first, to our knowledge, nationally consistent inventory of US on-road $\mathrm{CO}_{2}$ emissions built from bottom-up source activity data, DARTE not only establishes a national benchmark for the monitoring, reporting, and verification of emissions that are vital to regulating GHGs but provides previously unidentified insights into how key features of urban areas contribute to climate change. DARTE can provide valuable information to local and regional climate change mitigation initiatives (e.g., state and city climate action plans) $(6,41$, 42) whose success turns on the ability to assess both city-scale GHG emissions and their responsiveness to policy accurately.

\section{Methods}

Our emissions estimation procedure is based on a comprehensive dataset of roadway-level traffic volumes recently made available by the HPMS. The raw data are average annualized daily traffic (AADT) on more than 1 million road segments measured annually by state departments of transportation. The AADT is a measure of average daily traffic that takes account of seasonal and day-of-the-week variation, such that annual VMT for each segment can be directly obtained by multiplying AADT by the length of the segment and the days in the year. We aggregated VMT by county and functional class of roadway for each year. HPMS records comprise roughly $80 \%$ of all VMT, but the records do not contain comprehensive traffic data for most minor and local roads at the roadway level. For these smaller road classes, we used statelevel VMT by functional class from the FHWA's Highway Statistics Series (18) for rural and urban minor collectors and local roads, and allocated this VMT to each county in proportion to the county's share of total state VMT as reported in the HPMS.

The resulting time series of VMT by county and functional class was quality controlled to identify and adjust any outliers or structural breaks. In some cases, an apparent structural break occurred when a county or state reclassified roads to a different functional class, thereby shifting a significant amount of VMT to that new class. In those cases, there was no observed break in the state's time series for total VMT, so we performed no filtering and the data were preserved. To identify the data quality issue, our algorithm identified large annual changes in VMT for a given county and functional class where there were no oppositely signed changes observed in other functional class roads for that county. Where the year-on-year difference between the reported value and both the previous year and following year was larger than twice the mean annual change in VMT for that county and road time series, the observation was removed and replaced with an imputed value obtained by fitting a locally weighted scatter plot smoothing curve to the full time series minus the removed value (SI Appendix).

We used VMT to calculate fuel use and associated $\mathrm{CO}_{2}$ emissions. Fuel consumption per mile traveled varies substantially by type of vehicle, so VMT was partitioned across five vehicle classes and five road functional classes using data from Highway Statistics Series Table VM-4 (19). Table VM-4 provides state-level data on VMT by vehicle class, but the table is only available for 1993-1997 and 2009-2012. For the remaining years, we 
developed a calibration routine to impute state-level vehicle shares by functional class. We initialized the calibration using data on state-level fuel consumption (43), average vehicle fuel economy (17), and the shares of gasoline and diesel fuel truck VMT (44). The algorithm adjusted initial vehicle shares and fuel economies such that the calculated state-level gasoline and diesel fuel consumption totals were within $5 \%$ of values reported in Highway Statistics Table MF-21 (43). We used the calibrated fuel economies and VMT by vehicle type to calculate gallons of motor gasoline and diesel fuel consumed. Fuel consumption was then converted to $\mathrm{CO}_{2}$ emissions for each year, county, and road functional class using EPA emissions factors for motor gasoline and diesel fuel (45).

We assigned emissions to a geographic information system (GIS) layer of the US road network obtained from the 2012 Census TIGER/Line geodatabase (46). To maintain a consistent spatial framework, the road network used is the same for all years. Urban roads were defined as any road link that intersected or was contained within the boundaries of the 2000 Census Urbanized Areas and Urban Clusters shapefile (47). In 2011, the HPMS changed to a GIS-based reporting format, with a subset of AADT now

1. DeCicco J, Fung F, An F (2006) Global Warming of the Road: The Climate Impact of America's Automobiles (Environmental Defense Fund, New York).

2. US EPA (2014) Inventory of U.S. Greenhouse Gas Emissions and Sinks: 1990-2012 (US Environmental Protection Agency, Washington, DC), Rep No EPA 430-R-14-003.

3. Gately CK, Hutyra LR, Wing IS, Brondfield MN (2013) A bottom up approach to onroad $\mathrm{CO} 2$ emissions estimates: Improved spatial accuracy and applications for regional planning. Environ Sci Technol 47(5):2423-2430.

4. Andres RJ, et al. (2012) A synthesis of carbon dioxide emissions from fossil-fuel combustion. Biogeosciences 9(5):1845-1871.

5. National Research Council, Committee on Methods for Estimating Greenhouse Gas Emissions (2010) Verifying Greenhouse Gas Emissions: Method to Support International Climate Agreements (National Academies Press, Washington, DC).

6. Rosenzweig C, Solecki W, Hammer SA, Mehrotra S (2010) Cities lead the way in climate-change action. Nature 467(7318):909-911.

7. Hutyra LH, et al. (2014) Urbanization and the carbon cycle: Current capabilities and research outlook from the natural sciences perspective. Earth's Future 2(10):473-495.

8. Schuh $A E$, et al. (2010) A regional high-resolution carbon flux inversion of North America for 2004. Biogeosciences 7:1625-1644.

9. McKain K, et al. (2012) Assessment of ground-based atmospheric observations for verification of greenhouse gas emissions from an urban region. Proc Natl Acad Sci USA 109(22):8423-8428.

10. Andres R, Marland G, Fung I, Matthews E (1996) A $1^{\circ} \times 1^{\circ}$ distribution of carbon dioxide emissions from fossil fuel consumption and cement manufacture, 1950-1990. Global Biogeochem Cycles 10(3):419-429.

11. Brenkert AL (1998) Carbon Dioxide Emission Estimates From Fossil-Fuel Burning, Hydraulic Cement Production, and Gas Flaring for 1995 on a One Degree Grid Cell Basis (Carbon Dioxide Information Analysis Center, Oak Ridge National Laboratory, Oak Ridge, TN).

12. Blasing TJ, Broniak C, Marland G (2005) State-by-state carbon dioxide emissions from fossil-fuel use in the United States 1960-2000. Mitigation and Adaptation Strategies for Global Change 10:659-674.

13. Rayner PJ, Raupach MR, Paget M, Peylin P, Koffi E (2010) A new global gridded Data set of $\mathrm{CO}_{2}$ emissions from fossil fuel combustion: Methodology and evaluation J Geophys Res 115:D19306.

14. JRC/PBL (2011) Emission Database for Global Atmospheric Research (EDGAR) (European Commission, Joint Research Centre/Netherlands Environmental Assessment Agency, Ispra, Italy), Version 4.2. Available at edgar.jrc.ec.europa.eu. Accessed May 1, 2014

15. Asefi-Najafabady S, et al. (2014) A multiyear, global gridded fossil fuel $\mathrm{CO}_{2}$ emission data product: Evaluation and analysis of results. J Geophys Res Atmos 119:10,213-10,231.

16. JRC/PBL (2011) Emission Database for Global Atmospheric Research (EDGAR) Factsheet-Energy: Combustion in 1A3b (European Commission, Joint Research Centre/ Netherlands Environmental Assessment Agency, Ispra, Italy). Available at edgar.jrc.ec. europa.eu/factsheet_1a3b.php. Accessed June 20, 2014.

17. Federal Highway Administration (2013) Highway Statistics Series Table VM-1; 1980-2012 (US Department of Transportation, Washington, DC). Available at www.fhwa.dot.gov/ policyinformation/statistics. Accessed July 1, 2013.

18. Federal Highway Administration (2013) Highway Statistics Series Table VM-2; 1980-2012 (US Department of Transportation, Washington, DC). Available at www.fhwa.dot.gov/ policyinformation/statistics. Accessed July 1, 2013.

19. Federal Highway Administration (2013) Highway Statistics Series Table VM-4; 1980-2012 (US Department of Transportation, Washington, DC). Available at www.fhwa.dot.gov/ policyinformation/statistics. Accessed July 1, 2013.

20. Jones C, Kammen DM (2014) Spatial distribution of U.S. household carbon footprints reveals suburbanization undermines greenhouse gas benefits of urban population density. Environ Sci Technol 48(2):895-902.

21. Brondfield MN, Hutyra LR, Gately CK, Raciti SM, Peterson SA (2012) Modeling and validation of on-road $\mathrm{CO}_{2}$ emissions inventories at the urban regional scale. Environ Pollut 170:113-123.

22. McDonald BC, McBride ZC, Martin EW, Harley RA (2014) High-resolution mapping of motor vehicle carbon dioxide emissions. J Geophys Res Atmos 119:5283-5298.

23. Cervero R, Kockelman K (1999) Travel demand and the 3Ds: Density, diversity, and design. Transport Res D Transp Environ 2(3):199-219. reported in a GIS road network geodatabase. To maintain consistency across all years in our study, we extracted VMT from the 2011 and 2012 HPMS geodatabase and merged it with our 1980-2010 HPMS database. Roadwaylevel emissions were aggregated to a $1-\mathrm{km}$ grid, a $0.01^{\circ}$ grid, a $10-\mathrm{km}$ grid and a $0.1^{\circ}$ grid for comparison with the Vulcan Project and EDGAR inventories. The high-resolution grids nest smoothly within the lower resolution Vulcan Project and EDGAR grid systems for ease of comparison and to allow for the combination of DARTE on-road emissions with other sector emissions from either of those inventories.

ACKNOWLEDGMENTS. We thank Robert Rozycki from the Federal Highway Administration for providing us with access to the Highway Performance Monitoring System archives. We also thank Steve Wofsy, Ranga Myneni, and Tony Janetos for their feedback on this manuscript. Funding for this study was provided by NASA through Awards NNX12AM82G and NNH13CK02C by the National Science Foundation through Awards 1149471, 1430145, 1038907 and 1240507; and through Department of Energy Grants DE-FG02-06ER64204 and DE-SC005171.

24. Bento AM, Cropper ML, Mobarak AM, Vinha K (2005) The effects of urban spatial structure on travel demand in the United States. Rev Econ Stat 87(3):466-478.

25. Brownstone D, Golob TF (2009) The impact of residential density on vehicle usage and energy consumption. J Urban Econ 65:91-98.

26. Ewing R, Cervero R (2010) Travel and the built environment. J Am Plann Assoc 76(3): 265-294.

27. Cervero R, Murakami J (2009) Effects of built environments on vehicle miles traveled: Evidence from 370 US urbanized areas. Environ Plan A 42:400-418.

28. Newman P, Kenworthy J (1989) Cities and Automobile Dependence: An International Sourcebook (Gower, Aldershot, UK).

29. National Research Council, Transportation Research Board, and National Research Council Board on Energy and Environmental Systems (2009) Driving and the Built Environment: The Effects of Compact Development on Motorized Travel, Energy Use, and $\mathrm{CO}_{2}$ Emissions (National Academies Press, Washington, DC).

30. Duranton G, Turner MA (2011) The fundamental law of road congestion: Evidence from US cities. Am Econ Rev 101(6):2616-2652.

31. Cao X, Mokhtarian PL, Handy SL (2009) Examining the impacts of residential self-selection on travel behaviour: A focus on empirical findings. Transport Reviews 29(3):359-395.

32. Federal Highway Administration (2012) Archived Data from the Highway Performance Monitoring System (US Department of Transportation, Washington, DC).

33. Gurney KR, et al. (2009) High resolution fossil fuel combustion $\mathrm{CO}_{2}$ emission fluxes for the United States. Environ Sci Technol 43(14):5535-5541.

34. Gurney KR, et al. (2010) Vulcan Science Methods Documentation, Version 2.0 Available at vulcan.project.asu.edu/pdf/Vulcan.documentation.v2.0.online.pdf. Accessed September 1, 2014

35. Mendoza D, et al. (2013) Implications of uncertainty on regional $\mathrm{CO}_{2}$ mitigation policies for the US onroad sector based on a high-resolution emissions estimate. Energy Policy 55:386-395.

36. Battelle Institute (2004) Traffic Data Quality Measurement-Final Report, Prepared for the Office of Highway Policy Information, US Department of Transportation (US Department of Transportation, Washington, DC).

37. Office of Highway Policy Information, Federal Highway Administration (2010) High way Performance Monitoring System Field Manual (US Department of Transportation, Washington, DC), Available at www.fhwa.dot.gov/ohim/hpmsmanl/hpms. htm. Accessed May 1, 2013.

38. United Nations, Department of Economic and Social Affairs, Population Division (2014) World Urbanization Prospects: The 2014 Revision (United Nations, New York), CD-ROM Ed.

39. Sims R, et al. (2014) Climate Change 2014: Mitigation of Climate Change. Contribution of Working Group III to the Fifth Assessment Report of the Intergovernmental Panel on Climate Change, eds Edenhofer O, et al. (Cambridge Univ Press, Cambridge, UK and New York).

40. International Energy Agency (2013) Policy Pathways: A Tale of Renewed Cities (International Energy Agency, Paris)

41. California Global Warming Solutions Act (Assembly Bill 32) Health and Safety Code Sect. 38500-38598 (2006). Available at www.arb.ca.gov/cc/docs/ab32text.pdf. Accessed September 1, 2014

42. City of Boston (2010) City of Boston Climate Action Plan. Available at www.cityofboston gov/climate/bostonsplan/. Accessed May 1, 2013.

43. Federal Highway Administration (2013) Highway Statistics Series Table MF-21; 1980-2012 Federal Highway Administration (US Department of Transportation, Washington, DC) Available at www.fhwa.dot.gov/policyinformation/statistics. Accessed July 1, 2013.

44. US Census Bureau (2003) Vehicle Inventory and Use Survey; 1982-2002 (US Census Bureau, Washington, DC). Available at https://www.census.gov/svsd/www/vius/products. html. Accessed July 1, 2013.

45. Energy Information Administration (2007) Documentation for Emissions of Greenhouse Gases in the U.S. 2005, Table 6-1. DOE/EIA-0638 (Department of Energy, Washington, DC).

46. US Census Bureau (2012) TIGER/Line Shapefiles (US Census Bureau, Washington DC) Available at www.census.gov/geo/maps-data/data/tiger-line.html. Accessed July 1, 2013.

47. US Census Bureau (2003) Census 2000 Urban and Rural Classification (US Census Bureau, Washington, DC). Available at https://www.census.gov/geo/reference/ua/ urban-rural-2000.html. Accessed July 1, 2013. 